International Journal of Child, Youth and Family Studies (2012) 4.1: 546-568

\title{
FROM THERE TO HERE: USING PHOTOGRAPHY TO EXPLORE PERSPECTIVES OF RESETTLED REFUGEE YOUTH
}

\section{Jody Lynn McBrien and Rebecca Day}

\begin{abstract}
Because refugee numbers are much smaller than those of other immigrant populations in the United States, researchers frequently group refugees with other immigrants in their studies. However, due to the traumatic circumstances that most refugees face prior to their arrival, they require separate consideration. We chose the medium of photography to help newcomer refugee students express themselves beyond their current capacities in English, and we used the students' photographs as catalysts to interview them about their resettled lives in the United States. Through this process, we discovered themes central to the students' lives, and ways in which they were working to reconcile important past and present elements, such as family, friends, cultures, and aspirations. Bronfenbrenner's (1986) ecological theory provides a useful frame for exploring these students' processes of acculturation. Their photos, and their commentaries, provide critically important information for teachers, social service providers, and others working with refugee youth.
\end{abstract}

Keywords: resettled refugees, acculturation, ecological theory, photography

Acknowledgements: The authors wish to thank the University of South Florida Office of Research for the Internal Grant Award that partially funded this research project. They would also like to acknowledge the generosity of a local organization's refugee program staff that provided months of support.

Jody Lynn McBrien, Ph.D. (the corresponding author) is an Assistant Professor of Education at the College of Education, University of South Florida, Sarasota-Manatee, 8350 North Tamiami Trail, B322, Sarasota, Florida, U.S.A., 34243. Telephone (941) 359-4635; Fax (941) 359-4887. Email: jlmcbrien@sar.usf.edu

Rebecca Day received her MSW at the University of South Florida and currently works as the Mental Health Liaison at the Public Defender's Office, $6^{\text {th }}$ Judicial Court of Florida.

Email: rebeccaday@wearthehope.org 
International Journal of Child, Youth and Family Studies (2012) 4.1: 546-568

Interviewer: What do these photos tell me about your life in America?

N., 16-year-old female student, Liberia: That my dream will come true.

Annually, only about one percent of the world's refugee population is permanently resettled in a new country. Out of a reported 98,800 refugees receiving third-country resettlement in 2010, the United States resettled 73,293, with the largest numbers coming from Iraq, Burma, and Bhutan (Martin, 2011). Children under the age of 18 represent about $47 \%$ of all refugees, with $11 \%$ under the age of 5 . Although the United States permanently resettles more refugees than all other countries combined, the numbers are small in comparison to all immigrants resettled yearly. For instance, in 2011, there were a total of 1,062,040 people who obtained legal permanent resident status (Monger \& Yankay, 2012). Of that number, 113,045 were refugees, or $11.6 \%$ of the total figure. (The number of refugees differs from United Nations figures; Department of Homeland Security figures include some who arrived in earlier years). Thus, it is perhaps not surprising that many researchers who examine issues affecting school-age immigrant children include refugee children. Given traumatic backgrounds that frequently include war, torture, and other violent events, refugee children incur needs for support beyond other immigrant peers.

Many refugee families learn only a handful of English phrases prior to their arrival in the United States (Bebic, 2009). Cummins’ (1981) research with immigrants indicated that conversational skills are generally acquired within two years, but it takes five to seven years for students to reach academic fluency. Thus, it is difficult for newly arrived refugee youth to express their complex thoughts about resettlement in English. To understand the acculturation experiences of recently arrived refugee youth, we asked 17 refugee students from three counties in Florida, the state that currently resettles the largest number of refugees (Florida Department of Children and Families, 2012), to record their impressions of life in the U.S. using digital cameras. Specifically, we asked the students to take photos that capture daily experiences since resettlement. We then interviewed the students about photos that they chose to discuss, asking them what the photos said about their lives, and we had them choose their top three favorite photos to be framed for public exhibitions.

We also asked the participants to write two essays: one about their experiences coming to the United States; and another about what they want to do with their newfound freedoms, based on a question posed at the end of a U.S. Citizenship and Immigration Services film. Our purpose was to explore the interests, concerns, and challenges of recently resettled refugee youth through the catalyst of photography. We hoped to learn about ways in which these refugee youth were adapting to their lives in Florida. It was also our intent to provide the students with multiple forums to give voice to their feelings, needs, and aspirations, pictorially and verbally. The opportunities came through workshops, interviews, and public displays of the photos.

Our data collection included 2,650 photographic images, 17 individual interviews with the refugee students, two focus group interviews with the students, 27 essays written by the students during photo workshops, one focus group with some parents of the students, eight 
International Journal of Child, Youth and Family Studies (2012) 4.1: 546-568

refugee staff interviews, and four media interviews with students based on their photography. These numerous and diverse sources of data have taught us much about refugee youths' preoccupations, interests, cares, and daily lives.

\section{Photography as a Research Tool}

Photography has served as the basis for understanding segments of the population, including refugees, in other studies (Armstrong, 2005; Gallo, 2002). It has also been used to give a public voice to populations who are typically marginalized. Perhaps the most famous example is the documentary Born into Brothels (Briski \& Kauffman, 2004). The film chronicles the lives of several children born to prostitutes in Calcutta and the photos they take of their lives in the brothels. Briski also founded Kids with Cameras, a nonprofit organization that seeks to empower children in marginalized communities.

Other projects and studies on the role of photography in refugee research have concluded that art serves as a catalyst to increase communications and authentic voice, and to bring out themes of hope. In 2000, the United Nations High Commissioner for Refugees (UNHCR) held a public exhibition of 88 photos taken by refugees in Azerbaijan. The concept for the project came from staff of the magazine Azerbaijan International, who "realized that refugees could tell their own story better than any outsider could” (Azerbaijan International [AI], Winter 2000). The United Nations press officer for the event, Vugar Abdusalimov, commented that "the beauty of the exhibit is that one can see a glimmer of hope in so many of the photographs" (AI, Winter 2000). Yohani (2008) used photography as an intentional intervention designed to help refugee children recognize their feelings of hope. Similar to Noland (2006), Yohani noted that reflection on the photos brought about an increased positive self-awareness for some of the participants. Hope was a theme we found in interviews about the refugee youths' photographs, as well as in their essays.

Del Valle, McEachern, and Sabina (1999) utilized art therapy to learn about the experiences and concerns of Cuban refugee children who entered the United States by raft or after being detained at the Guantanamo Naval Base. Children recounted stories of seeing relatives killed by sharks, drowned, or shot by government officials. Their writing included themes of sadness about leaving friends and family, as well as happiness to find freedom in the United States. Kirova and Emme (2006) also examined the experiences of immigrant children entering school in a new country for the first time. The photos taken by these English language learners served as the non-linguistic vehicle for them to tell their stories. They concluded that photography is a way of capturing experiences that are not readily accessible through language.

Brekke (2003) asked nine asylum-seekers in Sweden to photograph their day-to-day experiences to study activities and coping strategies that could be useful once the refugees were resettled. He found that photography served to begin a reflective process on the part of the participants, making interviews more fruitful. The use of the photos made the participants more at ease and they improved the balance between the researcher and the informants, as the photographers were the experts about their own pictures. As we will discuss, students in our project seemed at times surprised by the images they captured in their everyday photos, and reflecting on them caused the participants to draw some new conclusions about their lives. 
International Journal of Child, Youth and Family Studies (2012) 4.1: 546-568

\section{Theoretical Frameworks}

Much current research on refugee children has a strong focus on challenges of acculturation (Roytburd \& Friedlander, 2008; Shriberg, Downs-Karkos, \& Weisberg, 2012; Trickett \& Birman, 2005). Acculturation is defined as the "process by which individuals change their behavior and attitudes towards those of the host society" (Barona \& Miller, 1994, p. 155). Researchers have explored this adaptation to a new culture and described various nuances in the process. For instance, Berry (1974) described four potential pathways to cultural adaptation: assimilation (renouncing one's native culture in order to adopt the views and behaviors of those in the dominant culture); separation (a preference for preserving one's own culture while rejecting that of the new society); marginalization (in which one embraces neither the homeland culture, nor that of the new environment); and integration (in which components of native and new cultures are embraced). Gibson (1998) described a strategy she termed "accommodation and acculturation without assimilation” (p. 623) in which voluntary immigrants choose to add to their native heritage by acquiring new cultural tools. Portes and Zhou (1993) posited the theory of "segmented assimilation" to explain three adaptation theories (a "straight line" pattern of upward mobility, a combination of upward mobility and ethnic solidarity, or a downward spiral into poverty), depending on social, political, and economic factors.

The combined work of these and other researchers of cultural adaptation indicate that the process is complex, and that a host of factors create a myriad of potential outcomes. The "stages" of acculturation do not typically occur in a linear manner: Daily contrasting experiences and settings of acceptance, rejection, support, and limitations can cause refugees to welcome cultural change one day and cling to their home culture the next. Children face the immense challenge of realigning their sense of identity to incorporate components of their host culture while maintaining some connection to their native roots. A critical factor for children is the amount and types of social support and services they receive and whether they ultimately feel welcomed or rejected by members in their host society (McBrien, 2005; Stewart, 2011). One of many ways refugee agencies and other social service providers are helping refugee children is through media of creative expression and art therapy. Research by Rousseau, Lacroix, Singh, Gauthier, and Benoit (2005) outlines the importance of pairing a verbal and nonverbal means of expression. This allows children the opportunity to express themselves through two different means and minimize the language barrier. Therefore, the pairing of photography and written words can be compelling when working with refugee youth.

Considering ways in which social frameworks can help or hinder cultural adaptation and identity formation, Bronfrenbrenner's (1986) ecological systems model postulates that individuals are a product of multiple environmental realms, and each aspect of that environment has an effect on a person's development. The theory addresses five different levels: the microsystem, which focuses on the people and settings that have an immediate impact on the child (and on whom the child can most have an impact); the mesosystem, which explains interrelationships among settings (e.g., between home and school); the exosystem, those that have an indirect effect on the child (such as a parent's workplace); the macrosystem that includes the aspects that make up an individual's culture and customs; and finally, the chronosystem that allows for an analysis of chronological development not only within individuals, but also in the 
International Journal of Child, Youth and Family Studies (2012) 4.1: 546-568

environment, and the interplay between the two. For refugees, obvious examples would include life transitions such as events causing them to flee from their homelands, the loss of family members and friends, and beginning over in new countries and cultures.

The theory highlights the different environments that can have an impact on a child's development and demonstrates the reciprocal nature of each level (Yohani, 2008). For instance, a family's cultural values can affect the way in which parents and children interact with the workplace, schools, friends, people of the opposite sex, etc. Thus, the theory addresses the complex issues of acculturation through a systems perspective.

\section{Methods}

Because we were trying to understand the meaning and nature of refugee youths' experiences as resettled refugees in the U.S., we chose qualitative research methods (Strauss \& Corbin, 1998). Funding allowed us to select 18 students, six from each of three counties in Florida. One dropped out of the study, and we allowed a young primary school student to be part of the photo project and workshops, but we did not include data from her photos or interviews. Students were chosen based on recommendations from our community partner that offered programs for refugee youth. Staff members chose students who displayed characteristics of high participation in programs offered to refugee youth by the agency. Students represented the following countries of origin: Albania $(n=2)$, Burma (1), Colombia (4), Cuba (4), Liberia (3), Sudan (2), and Vietnam (1). This country range is representative of the refugee population in west central Florida. The students had lived in the U.S. between three months and four years at the beginning of the project. The median time in the United States was 25 months and the average was just under 26 months. The ages ranged from an 11-year-old boy from Liberia to the oldest, a young Burmese man who was 17. However, the median age was 14, and the average age was 13.7.

In focus groups with community partner staff, we determined the organization of our meetings with the participants. For our first meeting, we included parents to go over informed consent, handed out the digital cameras, and explained their use, engaging Spanish, Vietnamese, and Burmese interpreters as necessary. We gave the students an exercise in using the cameras and took them outside to practice techniques. A month later, we asked the students to bring their cameras to the community center where we downloaded the photos and interviewed students individually. While students were waiting to be interviewed, they wrote essays about "coming to America” included in our data analysis. They worked with professional and highly trained amateur photographers who volunteered to assist the participants with photography skills.

At a third session, students chose their three favorite photos to be framed and exhibited, first at a public city gallery, and then at a university. They were again assisted by volunteer experts in photography, as well as interpreters when needed. While waiting, the students watched a new U.S. Citizenship and Immigration Services film. The end of the film poses the question, "What will you do with your freedom?" which participants addressed in an essay. At this session, we told the students that they could keep their cameras. Three months later, the students and their families were invited to the opening of the photo exhibit at a city gallery. Over 200 people attended the opening event. Six months after the opening of the city exhibit, we held a 
International Journal of Child, Youth and Family Studies (2012) 4.1: 546-568

final pizza party for the participants and their families in which we returned the framed photos to them and held focus group interviews with the 10 students in attendance (four had moved out of the area with their families, and three were unable to attend).

We used Strauss and Corbin's (1998) open-ended coding approach, allowing themes to emerge from the data rather than beginning with a prescriptive list of expected codes. We believed this would be a better way to discover the settings and topics of most importance to the participants. However, we also acknowledge that we were likely to be influenced by our research interests in the students' adaptation to life in the United States. To reduce bias, we coded independently, and we asked a refugee staff member and two of the student participants to respond to our findings. We also relied on techniques described by Strauss and Corbin (1998) to reduce bias. These included "giving voice" to our participants and rendering their own words as much as possible in our findings (p. 43). We also used multiple viewpoints and data, in terms of collecting data over different times and in different places; talking with staff as well as students; and using photos, interviews, and essays as we categorized themes. We compared what we found to conclusions suggested by the research literature mentioned above.

We conducted numeric and interpretive content analyses on the data (Cohen, Manion, \& Morrison, 2007). With transcribed interviews and essays, we used Weft QDA, an open source tool for qualitative text analysis to code discrete categories and search for instances of key terms corresponding to themes we found in photos and those that correspond to issues of youth acculturation. For example, we searched 14 words related to "family" (including parent, mother/mom, father/dad, brother, sister, cousin, grandmother/grandma, grandfather/grandpa) and found 404 references in at least 22 of the transcribed documents. Words relating to education (school, education, learn, student, college, university) totaled 168 references in at least 23 documents. Other important key terms are included in the following table:

Table I: Key Term Searches in Interviews and Essays

\begin{tabular}{lll}
\hline Key term & Total references & Total documents \\
Family-related words & 404 & 22 \\
Aspiration-related terms & 212 & 23 \\
United States/U.S./America & 196 & 22 \\
& & \\
Education-related terms & 168 & 23 \\
Friend & 105 & 22 \\
Change & 58 & 20 \\
Home & 35 & 18 \\
Language & 29 & 18 \\
\hline
\end{tabular}

The top themes recorded in the photos were friends, family (and celebrations, most commonly with family), nature and art, and school and education. The subjects have a direct relationship to systems levels described by Bronfenbrenner $(1979,1986)$. Many photos fell into multiple possible codes, such as pictures of family and friends at a celebration, or photos of nature taken during outings. Linguistic explanations delivered through interviews and essays, 
interwoven with the photographic themes, included concern for and appreciation of family, importance of friends (and missing homeland friends), awareness of homeland dangers, acculturation challenges, and hope.

It was not possible to create a mutually exclusive matrix of domain categories depicted in photographic, written, and oral data, as can be seen in Table II. For example, photographic examples coded as "culture" included images such as flags, traditional meals, and religious symbols. Most photos of "celebrations" could have been included with culture, as they included birthdays, weddings, and graduations. Some participants used photos they took of nature as metaphors to discuss changes in their lives. Some ambitions were related to education. Far from fixed, static categories, we interpret the major themes that arose from the data as fluid and multilayered; thus, the numbers are rough approximations.

\section{Table II: Codes by Theme}

\begin{tabular}{llc}
\hline Major Themes & In Photographs & In Interviews and Essays \\
Family & 320 & 404 \\
Friends & 444 & 105 \\
Culture & 204 & 220 \\
Education & 209 & 168 \\
Celebrations & 249 & 30 \\
Outings & 228 & -- \\
Aspirations & -- & 212 \\
Nature & 158 & -- \\
Reflections on Life Changes & -- & 58 \\
\hline
\end{tabular}

\section{Limitations}

In the section that follows, we will report our findings from interviews, essays, and the themes found in photo images taken by the students. We acknowledge several limitations. First, the primary researchers were not well acquainted with the participants. Positivist perspectives remain dominant along with the belief that personal distance is best for acquiring "objective" results (Cohen et al., 2007, ch. 1). However, given the contexts of fear and uncertainty in the lives of refugees, issues of trust are considerable, and access to authentic information may only be achieved once relationships are established between researchers and refugee participants (Miller, 2004). Thus, some of the interview material may not always have been as detailed or rich as it could have been were the students more familiar with us.

We used several procedures to compensate for this problem. First, we gained access to the students through an agency and personnel who were well acquainted with and trusted by the students and their families. Second, the project took place over a nine-month time period; thus, there was a sense of stability created for both students and parents. We created a fun atmosphere for the students that allowed them to feel relaxed and safe by including food, activities, and peer conversations. The participants were allowed to take their cameras on field trips that were organized by the refugee agency if they chose to do so (such as to zoos, amusement parks, and the beach). We had not only the photos, but also interviews and essays of the students for data. 
International Journal of Child, Youth and Family Studies (2012) 4.1: 546-568

We also held interviews with caseworkers to ask about ways in which they noticed changes in the students as a result of participating in the photo project.

As a second limitation, it became clear that our participants did not take every picture that we downloaded from their cameras. In one case, a student told us that he had his mother take the camera to her place of work where nearly 50 photos were taken. We eliminated those from the study. In other cases, however, participants asked others to take photos because they were of interest to the participant him or herself. These include photos of the participant.

Thirdly, we are aware of external factors that could have influenced the participants' comments and essays. The youth were certainly aware that they were part of a small group chosen for the project, and they could have been trying to please the adults and caseworkers involved with the project. The whole notion of "freedom" is problematic, as the U.S. Citizenship documentary projects a very pro-American stance and value system regarding the concept of freedom. However, all of the youths' comments were not positive or happy, as noted in the findings, so we believe we have captured many genuine concerns as well as acculturation progress amongst the population with whom we worked.

Finally, as with most qualitative studies, our research is not generalizable. We worked with a small number of refugee students who were selected by criteria (middle school and high school youth that the refugee staff believed would be responsible with the cameras and follow through on the project). The criteria of responsibility, one we believed essential as we were distributing cameras valued at over $\$ 100$, necessitated excluding youth whom refugee staff felt would be less likely to complete the project. This criterion may have excluded youth having more difficulties adapting than those chosen for the project. However, our participants included refugee youth who experienced acculturation difficulties, noted by self-report, interviews with staff, or interviews with parents. Though we did not specify criteria based on gender or country of origin, we were fortunate to have an equal number of males $(n=9)$ and females (8), nearequal numbers from the three counties served by the refugee agency, and a fairly representative distribution of the refugee population in the area by country of origin.

\section{Findings}

In the following sections, we exemplify major themes as depicted in the photographs, interviews, and essays. The themes depict not only people and places that are important components of children's microsystems, but also ways in which the system layers interrelate.

\section{Theme One: Family}

In difficult times, family is the most important source of peace and joy. People are not unlike trees - they grow wherever wind takes their seeds and they develop strong roots on good land. C., 14-year-old, Liberia (photograph of an extensive tree root system)

The greatest number of references from the photos, interviews, and essays combined related to family members. Nineteen out of 50 photos chosen for framing included family 
members as subjects or referred to family in captions. A 13-year-old male participant from Liberia chose family scenes at home for all his framed photographs. Each included his mother and younger sister. He chose them because of smiles in the picture, "the way my mom is looking", "the way my sister is trying to climb up my mom". One photo, a picture of his sister looking at a photo album on his mother's lap, notes the contrast of current and missing family members. He said, "I like this picture because my little sister was looking at a picture of someone she has never seen before and she knew who it was the first time she saw him. It was my dad in Africa”. This reflection suggests a bond with his missing father, as he imagines his 3year-old sister recognizes him despite no prior knowledge.

Eleven of the refugee youth specifically mentioned sadness due to missing family members who were still in their homeland or killed in violence. A 14-year-old male student from Albania told of how, when he was just 6, his father died in his arms after being shot to death. A 14-year-old male from Colombia related every image discussed during his interview to missing grandparents whom he longed to see again. A 15-year-old girl from Sudan talked about an older sister in Africa who was going to give birth and her sadness at not being there for the event. A recently arrived 12-year-old female student from Cuba cried when she said that her father, siblings, and grandparents were still in Cuba. Her photos, however, were filled with hopeful subjects: a birthday party with family and new friends, a church celebration, and a school celebration at which she won an award. The participants, through their tears, pauses, and indications of discomfort, indicated deep emotions about family members who remain important people in their lives. Most of the youth were unable to remain in touch with missing relatives, sometimes for political reasons, sometimes due to lack of technology in the home situations. Though these people are missing from the closest developmental systems' layers of these youths' lives, they play an important role through memory.

Brothers and sisters were frequent subjects of photos and interviews. The 14-year-old male from Albania had younger brothers, and during the interview he talked about guiding them:

Interviewer: So, you tell him things he needs to know?

A: Yeah, like read or do homework for the future so he can get a good job.

Others took photos of brothers or sisters with their friends, at celebrations (such as graduations), and at outings. Most comments about siblings were ones of pride or guidance (especially with younger siblings).

Photos of celebrations, such as birthdays and weddings, were frequently associated with family. Interestingly, even though some of these depicted major transitions in the lives of some participants (such as Quinceaños), only one, the graduation of a sibling, was chosen for framing and public exhibition. A related subject, outings, though photographed less than celebrations, was chosen more frequently for framing. In analyzing this point of data, we determined that it may not, in fact, reflect something about the participants' preferences. Even though the youth made the final selections on framing, we could not rule out some interference with selections as staff would make occasional persuasive comments while viewing photo images with participants. 
International Journal of Child, Youth and Family Studies (2012) 4.1: 546-568

\section{Theme Two: Friends}

H., 16-year-old female, talking about a photo she took of two flowers: When I look at the two flowers side by side it's like I remember my friends. They were always by my side.

Interviewer: In the Philippines?

H: Yes.

Dr: What would you like to say to them?

H: That no matter what happens, we'll be still friends.

By far the largest number of photographs taken were of friends, either at school, birthday parties or other celebrations, or outings organized by the refugee center. Seven of the framed photos included pictures of friends. Given that past interviews with refugee youth (McBrien, 2009) indicated that they befriend primarily other international students, it was interesting that so many photos showed great ethnic and racial diversity in friendships. For example, many photos included Hispanic or Black refugee students with White students. Photos with friends were captured at playgrounds, athletic fields, beaches, amusement parks, and classrooms. Describing his diversity of friends, a 12-year-old male from Colombia said, "[The photo] shows different types of friends. I mean, there is the little one, the tall one, the red-haired one, and the one that's turning [hair] colors". Later in the interview he stated, "You change countries, you change friends, you see new stuff, different stuff”.

Interview comments also described missed friends from the students' homelands. The 17year-old male from Burma, while looking at a photo of himself with friends at a St. Petersburg, Florida beach, remarked that it reminded him of friends left behind in Burma:

H: I miss it very much and sometimes I feel if they were here how it would be nice.

Interviewer: Who do you think of and miss from Burma?

H: My childhood friends who used to play with me. I miss my friends.

Interviewer: Yes. Do you get to talk to them on the phone?

H: I don't even know where they are now.

Similarly, a 14-year-old male from Colombia commented on how a photograph he took reminded him of missing friends:

Interviewer: What are some feelings that you have when you look at this picture?

L: My friend when I was in Colombia in my school and that he looked just like him. 
International Journal of Child, Youth and Family Studies (2012) 4.1: 546-568

Interviewer: Do you ever see that friend anymore? Do you hear from that friend or how he is doing?

L: No. It makes me sad.

This combination of gratitude for new friends and sadness at missing old friends was a frequent theme in the interviews. A 16-year-old female recently resettled from Cuba said she thought of her Cuban girlfriends as "friends forever" though she was unable to be in touch with them. Several staff members noted how the photo project helped their young refugee clients process this life change. For instance, one woman, in discussing her 16-year-old Cuban client, said,

When she started taking pictures, she became more aware of this country's opportunities and realized she has the opportunity for a new start. She realized things aren't so bad here. For example, she would see in her pictures, Oh, look at my friends; oh, we are having a good time!

Though the numbers were not as high as those for peer-aged friends, many youth took photos of staff members from the refugee organization. One student framed a photo of himself with his caseworker, commenting that her tutoring helped him receive the best grade in his class on a test. Other comments in interviews of the youth and their parents indicated much gratitude for the many ways that refugee staff helped the students and their families, for example as school liaisons, tutors, mentors, and family assistance providers.

\section{Theme Three: Cultures}

14-year-old Q. describes a photo he took of a shiny car wheel rim that is reflecting the outside environment: "In America, the rims matter more because they attract attention to your car and what you have."

We grouped several subcategories together that reflected participants' discussions of culture. They included comments and photos about their native cultures and U.S. culture, and comparisons they made between the two. These photos and comments indicate students' relationships at the macrosystem level (Bronfenbrenner, 1979). Captions of 20 photos students chose to frame directly addressed cultural issues. Several students took photos of TV screen shots including news about their homelands. Most notable were photos taken in May 2008 of the cyclone that killed hundreds in Burma by H., the 17-year-old Burmese refugee. H. chose not to discuss these photographs. However, during much of his interview he talked about friends and family left behind. H. spoke and wrote comparatively about freedom, education, and miscellaneous cultural differences. For example, during a field trip to a Florida beach, $\mathrm{H}$. took many photos of sunbathers. When asked about it, he queried in response, "Why are these people 'torturing' themselves by lying in the hot sun?” This habit was completely unfamiliar to him, and it seemed a foolish thing to do. In his essay about freedom, H. wrote,

First of all I will talk about education. I cannot study in my country even if I want to, because of financial problems. Even if I have money I cannot study with the people who are rich and who are different with my religion. But in America I can study freely with different status, different religion and different race. 
International Journal of Child, Youth and Family Studies (2012) 4.1: 546-568

H.'s family was struggling with finances, unemployment, and difficulties learning English. But he remained hopeful about new opportunities in comparison to his life in a Thai refugee camp.

Some students, in comparing their lives in the United States with their native countries, indicated their awareness of mortal danger from which they fled. Twelve-year-old R. from Colombia wrote about how she could now play outside without fear of kidnapping by guerillas. Thirteen-year-old $\mathrm{O}$. from Liberia wrote that he would like to use his newfound freedom to be educated so that he could return some day and "stop the killing and the raping, especially the war happening right now". Awareness of these violent crimes by so young a child indicates his personal trauma. O. indicated his awareness of political strife in his essay: "One of the presidents was mad because he wasn't elected to be president. A president was shot by another president so that's why the people declared war”. Twelve-year-old C. from Cuba took many photos of the gulf during a cloudy day. He frequently stated, "it is better to travel by plane”. He talked about his grandfather, who made a perilous journey by raft seeking asylum in the United States.

Other students were taken by the uniqueness of American culture. Ten-year-old S. from Liberia framed a photo of himself in a petting zoo. His caption stated, "In Liberia, you don't have to pay to go and see animals". Burmese H. took a photo of a large beach playground stating, “I’ve never seen a playground like it before”. Seventeen-year-old Y. from Sudan took a photo of a truck carrying crates of oranges and commented, "In Sudan the trucks carrying the oranges aren’t so large. Here they are so big and colorful”.

Other comments on American culture recognized the role of materialism. Many of the students took photos of their family or friends standing in front of their cars. Q., the photographer of the car wheel rim, took a photograph of a gas station sign advertising the cost of gas at \$3.95. He stated that the rising cost was preventing him from getting to friends' houses, because his parents could not drive him, given the expense. His 13-year-old brother, N., took photos of their older brother's jet ski.

Q. also noticed instances of American culture that struck him as positive benefits unheard of in his native Albania. For instance, his youngest brother needed surgery on one of his legs. Q. took pictures of the wheelchair and commented in a media interview that wheelchairs were uncommon in Albania because of the economy. He took photos of handicapped signs, stating that people did not care about these challenges so much in his native country. About his photo of a school bus, Q. discussed its central importance in his life.

Other students took photos, frequently with nature themes, that relayed contrasts between their former and current lives. For instance, 16-year-old H. from Vietnam took several photos of morning glories. She said the flower was different from morning glories in the Philippines, and added, "My life in the Philippines was different from here". A photo that we chose to advertise the public photo exhibitions was of a ripple in a pond reflecting the surrounding trees and sky. Its artist, 16-year-old O. from Cuba, captioned it, "Disturbance: Surprising of the change in my life”. She compared the ripple to major changes in her life right after her Quinceaño in Cuba. Her mother left for the United States, they were separated for a year, she changed schools, and then she was reunited with her mother in the U.S. She left behind friends and other family members. 
International Journal of Child, Youth and Family Studies (2012) 4.1: 546-568

\section{Theme Four: Education}

Interviewer: So, looking at these kids [photo taken of university students] because they are doing well makes you think you are going to do well. Why do you think they are good role models for you?

N., 15-year-old, Liberia: I feel it because I've seen them, I've looked at their pictures...

As noted in Table II, education was the fourth overall major theme depicted in photographs and discussed in interviews and essays. Nine of the photos students chose to frame had to do with school scenes. Reflections in photos, interviews, and essays related both to the students' former education experiences (prior to entering the United States), current schooling, and future aspirations. These descriptions involved ecological layers of the microsystem, mesosystem, and macrosystem.

Some photos were of school objects - buildings, grounds, buses. Fourteen-year-old N. from Cuba selected school-related subjects for all three of his framed choices. In his photo captions, he wrote, "It's about the circle of my life...my school, where I made friends and relationships; this hallway is the passageway to my life". Half of his interview focused on his feelings of connection to his school. Sixteen-year-old H. from Vietnam chose to frame a photo of one of her Vietnamese friends in an English for Speakers of Other Languages (ESOL) classroom. She explained that her friend, who knew little English, was working hard. Seventeenyear-old $\mathrm{H}$ from Burma, also discussed photos he took in his ESOL classroom. He explained that he had never done projects (such as molding a clay pot) before coming to his Florida school. In photos, interviews, and essays, he emphasized his joy at the opportunity to become educated, despite struggling with English.

Many photos of friends were taken in school - in classrooms, playing fields, and school celebrations. School was clearly connected with making new friends, as were events coordinated through the refugee services organization (such as picnics, beach, and theme park outings). Through these photos and the participants' comments, we found frequent indications of the students addressing macrosystemic culture and acculturation issues. For example, $\mathrm{H}$. from Burma discussed his desire to learn English so he could communicate with students in his classes. Indications at the mesosytemic level often involved school celebrations, such as school awards or graduation. These photos depict parents along with friends of the participants and their parents. People together in the photos typically represent several cultures brought together, noted through race, ethnicity, and sometimes clothing.

Future educational aspirations were depicted and discussed by many students who attended a field trip to a local university where they were met by current undergraduates. Fifteenyear-old N. from Liberia chose to frame a photo she took of university students on this field trip. On her label for the photo exhibit, she wrote, "These are my friends who go to University of _ . When I graduate from high school I'll go to a university myself to become a scientist”. 
International Journal of Child, Youth and Family Studies (2012) 4.1: 546-568

\section{Theme Five: Reflections on Life Changes}

Quotes from H., 16-year-old female student from Vietnam [about one of her photos of a large bridge over water]: In the beginning when it starts I don't know very much of America; it is like the bridge. I couldn't see how beautiful it is when I first saw it. And when I slowly go over it then I see. Sometimes just when I take pictures I realize that what a great thing is to be here that I don't see every day.

An especially important finding was our participants' reflections on changes in their lives, both because of the positive comments (in contrast to psychopathic research findings) and because of the sophistication of their observations, both positive and negative. In this category, we found that a number of participants used metaphors based on photographs to explain their resettled lives. Thus, they utilized concrete images to explain abstract concepts. These concrete images included ponds, bridges, paths, trees, flowers, and school images. Two students took pictures of paths or walkways, using them to describe pathways to their futures. Fourteen-yearold C. used the metaphor of trees and roots to describe the power of family, suggesting their ability to "transplant" - "they grow wherever wind takes their seeds" - and maintain a commanding presence and importance: "they develop strong roots on good land”. Sixteen-yearold H. from Vietnam took many photos of a bridge in the gulf and talked about how it represented ways of viewing her life. She spoke of different perspectives, depending on where she was when she viewed the bridge. She also discussed a flower representing her life: "from the beginning it was a small bud and later on it blooms to become a beautiful flower”.

Not surprisingly, some changes were not so positive. In our final group interviews with the participants, we asked them what they would like U.S. students and teachers to learn about them. The following is an excerpt from one of the focus group conversations:

Interviewer: What would you like to tell students in your school?

Student: Be more friendly. Sometimes we speak to some of them [U.S. students] and they like say go away from me because they think we are like animals, like we don't know how to be a person.

Interviewer: How did they treat kids in school if you don't speak the language or if you come from another country?

Student: Bad. I don't know - if there is a new kid, everyone goes and picks on them.

Student: Sometimes the teacher thinks we don't like to do our work. But if they gave us work and we didn't understand it, we couldn't do it. So sometimes they think we don't do work because we don't want to or we are just lazy.

In this theme we found clear recognition of life changes, and within that, participants' challenges with discrimination as well as their belief in positive growth and educational opportunities. 
International Journal of Child, Youth and Family Studies (2012) 4.1: 546-568

\section{Theme Six: Hope/Aspiration}

Finally, I can see the happiness of life after I came here and I know how life is precious. Therefore, I am very glad to be here in America. 17-year-old H., Burma

As we have explained in describing earlier themes, participants were open about their personal losses and sadness regarding their separation from homeland family and friends, awareness of past personal life danger, and current issues with language and prejudice. Thus, we found the numerous references to hope and future aspirations an important theme. Q. from Albania said he wanted to become an orthodontist because he could make "a lot of money and help my family". Twelve-year-old C. from Cuba wrote, "I want to become a lawyer so I can help children all over the world like this [refugee] program does”. Fifteen-year-old N. from Liberia wrote, "What I am going to do is to change the world? I will like to help the community, make them find answers to their problems and encourage them to speak out”.

Interviews with staff members and caseworkers at the refugee organization suggested an additional finding: Involvement with the photo project was related to positive changes in the students' lives. The caseworker for a 10-year-old male participant from Liberia said that he began as a "shy, quiet boy... whose older brother can be abusive". She noticed that $\mathrm{M}$. became "more confident and powerful because he had this camera and knowledge". The caseworker of N., a 14-year-old from Cuba, stated that he began as a reluctant participant, explaining that his parents were in the process of a divorce and that he had "actually been suicidal earlier in the year". She went on: "He took a picture of me and said that the camera was making memories of 'the people who love me'. He became very excited about the project as time went on and is doing much better". Another staff member who worked with N. stated that he had been "very depressed" and "barely talked to me". She also described a transformation in his outlook: "Now it’s like we're friends! He talks to me all the time. Now he's looking forward to the future...”.

H., the 17-year-old Burmese refugee, had lived in a primitive Thai refugee camp since infancy. At our first workshop, he struggled to receive translations via a cell phone while he tried to make sense of a digital camera. His caseworker said that through an interpreter, his father commented, “My son's not smart enough. Maybe we should just go home now”. In the end, H. took some of the best photos in the group in terms of artistic quality. The director of the refugee youth program noted his improvement:

In the second session when we did the first writing assignment he struggled to get out a couple of sentences on why he came to America, but in the last session when it came to what would he do with his freedom, I watched him as I was in and out of the room and he painstakingly worked at it for almost an hour to come up with a full page of what freedom meant to him. It was so focused on education, and he was determined to do it himself. He's a young man who has so much against him, and continues to make strides.

She commented that H's father was critical of him, and his large family had financial fears. These events create negative situations at the microsystem and exosystem layers of the ecological systems model. Both the director and the caseworker believed that his participation in the photo project raised H's self-esteem and his family's regard for him. 
International Journal of Child, Youth and Family Studies (2012) 4.1: 546-568

Though not poorly regarded by family, 16-year-old H. from Vietnam led a restricted life, according to her caseworker, and was not allowed to partake in extracurricular activities. She aspired to become a pharmacist and a photographer. She was a good student who received good grades, but according to her caseworker, "she sometimes feels like 'a bird in a cage' because she has so many school and family obligations. I was pleased that H's family allowed her to go for walks to take pictures of the flowers with her camera. ... This has been a good opportunity to have social time with her peers".

\section{Discussion}

The purpose of our research was to learn more about the acculturation of refugee youth in the United States using the medium of photography to see what they valued, what concerned them, and how they felt as they engaged with a new culture and lifestyle. Our methods fell within a research literature recognizing the value of photography in expressing views that students are sometimes unable to verbally express, sometimes because of current inabilities with the dominant language. As Q. from Albania said in an interview, "What I've learned from this photo project is that you can also show yourself with the camera, with pictures. You don't have to just say with words. You can also say things with a picture and explain to others”. We also recognize artistic expression as a medium capable of delving into emotions and concerns that might otherwise remain unsaid (Brunick, 1999; Kirova \& Emme, 2006). One of many examples came from 14-year-old C. from Colombia. Every photo he discussed, no matter what the image, caused him to recall the grandparents he longed to see again.

We found high replication between our research and previous work. Similar to Brekke (2003), we found the use of photography a helpful catalyst in facilitating the communication process. Our interviews revolved around the students' photos, and we asked them to select the photos they wanted to discuss in hopes of learning more about their chief concerns and interests. Along with Noland (2006), we found that asking students to take photos from their day-to-day lives allowed the participants to "speak for themselves" and to reflect on daily occurrences in a way that increased their own self-awareness. A caseworker identified this point clearly when she stated, "They realized so many things through the pictures and how things look. The pictures helped them to notice details that they weren't aware of before. They became more aware of their environment and settings and feeling better about their lives here”.

Del Valle, McEachern, and Sabina’s (1999) research with Cuban refugee children revealed the children's awareness and fears of the dangers through which they passed as they traveled to the United States on rafts. Likewise, our participants recalled dangerous and traumatic incidents in their lives as they worked with photography. Kirova and Emme (2006) found that photography helped their recent immigrant participants capture ideas and feelings that they could not yet express in a new language. Similarly, we found that many of our participants used photographs to express sophisticated abstract concepts, such as life changes, diverse perspectives, and aspirations through the use of nature photography and metaphors.

Finally, most of the participants in our photography research project described multiple expressions of hope, echoing the sentiments of Abdusalimov (AI Winter, 2000) and the conclusions of Yohani (2008). She wrote: 
Hopefulness as a subjective element of experience can be key in a child's ability to engage in meaningful activities that in turn contribute to psychosocial development. The implied links between hope, engaging in meaningful activities, and personal growth in Bronfenbrenner's theory suggest that hope may also assist with adjustment processes in the aftermath of or during stressful life experiences. (p. 312)

Yohani also found that parent responses to their children's involvement in arts-based interventions were positive, increasing the relationship between parent and child at the microsystems level. We were only able to interview three parents; thus, our data is more anecdotal than comprehensive, so we did not detail it in our findings section. However, each parent expressed pride at their children's photographic expressions. They also had high praise for the youth program and wished to see this project replicated for other refugee children.

Applying Bronfenbrenner's (1986) ecological systems model to our project, we found connections particularly at the microsystem, macrosystem, and chronosystem levels of interaction. Most frequent were data exemplifying relations between participants and their friends/peers, family, schools, and the refugee program. Photos showed positive situations, but interviews also turned up discussions of negative peer and teacher misunderstandings. Family photos were positive, as were most of the interviews. However, interviews with participants and staff also brought up critical and restrictive parental examples as well as family crises (divorce, unemployment, financial concerns, strict cultural practices). Most students expressed positive feelings towards education, but there were also comments about difficulties with English.

Mesosystem interactions surfaced in photographs and interviews in instances such as traditional foods and meals, religious practices, and cultural celebrations such as Quinceaños. And the chronosystem level of influence appeared as participants referred to the events that caused them to become refugees as well as the results of becoming refugees. These instances included war, deaths, the loss of family members and friends, and economic hardship.

As we consider acculturation theories in light of our research, we find evidence of assimilation and integration from Berry's (1974) framework. Our participants want to blend in with their U.S. peers. Simultaneously, they have pride in their native cultures and take part in traditional cultural events as seen through their photographs. Considering Portes and Zhou's (1993) theory of segmented assimilation, we observe these participants engaged in the combination of upward mobility and ethnic solidarity. Most participants spoke of school and education as a way of achieving economic and social goals. They spoke of these successes as ways of helping their families. And their desire to be reunited with missing family members and returning one day to their native countries indicated solidarity with their cultural origins.

Ultimately, what did we learn about the acculturation process with this small group of refugee youth in west central Florida? We discovered several important themes through a qualitative process of deriving themes from discrete data categories. One, we learned that they are influenced by considerable pain: the loss and inability to be in touch with family members and friends from their native countries; the trauma of death, war, separation, and ongoing uncertainty in their homelands; and discrimination and personal/economic uncertainty in their 
current lives. These associations occurred frequently in the majority of interviews with the students. Eisenbruch (1988) termed this grieving both personal and cultural bereavement. In his work on social adjustment for refugee children, he stated that effective programs respect the native cultures of refugee children and allow them ample time to adjust and learn the language of their new country. Eisenbruch argued that rapid acculturation could negatively affect children's ability to complete their grieving process and claim their cultural identity.

Second, we observed remarkable determination in our participants. They expressed their beliefs in education to lead them to promising careers. They spoke of their desires to contribute to social justice. They remarked on their desires to return to their homelands and to see lost family members. Thus, it is important not to reduce one's response to refugee children down to a simplistic deficit model of psychopathology. The students in our study struggled with grieving and the impacts of trauma. But they also showed high indications of resilience, particularly when offered the outlet of creativity and support resulting from the photo project. As mentioned in our limitations section, some positive student commentary may have resulted from their desire to please, fears of saying or doing something "wrong”, and the influence of a pro-U.S. agenda, as illustrated by a United States Government documentary.

Third, we noted their appreciation for the opportunity they had received by gaining refugee status in the United States. They commented on the importance of the freedom they gained. Several wrote about their desire to participate in national elections after becoming U.S. citizens. They recognized that their opportunities included the chance to have an advanced education. They realized that their new lives protected them from dangerous situations such as kidnapping, rape, and war that were common in their homelands.

Finally, we saw indications that the photo project itself resulted in positive changes in the lives of the participants. As noted by staff in the refugee youth program, some participants went from depression to hopefulness, or from negative attitudes to a belief that their lives in the United States were better than they had imagined. Throughout the workshops and activities (beach, amusement park, zoo outings, etc.), we saw positive interactions amongst the refugee students. The director told me that one of the participants told her he did not know there were other refugees in similar situations prior to engaging in the refugee youth program activities. This indicates how isolated many of these students are in their respective schools, and how important a refugee youth program is to their well-being.

\section{Implications for Practice and Research}

One clear result from our research is that teachers and social workers need to be aware of the unique circumstances that refugee students face as they attempt to acculturate into American society. Although the majority of photos taken by the children indicated hopefulness and optimism, there was also a strong undercurrent of the trauma many children experienced. The youth in our study wrote about and discussed rape, guerillas, war, killing, and the dangers of family members traveling by sea to get to America. They are aware of and have confronted instances of death, torture, and the loss of family and friends, as well as the common immigrant experiences of coping with language and cultural changes. These traumatic instances are never far from their minds. They had a sense of political situations as well as the violence that was 
occurring in their homelands. Yet, they indicated remarkable resilience in their wish to achieve their hopes and aspirations, especially given support from programmatic opportunities. Thus, it is critically important for educational institutions to be in touch and cooperative with social entities that offer refugee students opportunities to express themselves and to avoid entrenchment in immediate problems faced by their families, such as economic hardships. Because most teachers are not trained in professional responses to trauma, it is important for school administrators to create and provide successful links between teachers and mental health providers who understand the refugee experience (Szente, Hoot, \& Taylor, 2006). Areas with refugee populations tend to have agencies with departments that directly serve refugees. They may have adult refugees who act as liaisons between schools, homes, and community providers (McBrien \& Ford, 2012).

Our research has shown that photography can be a powerful medium when working with children, especially those who have a limited understanding of the culture and language. It offers a non-verbal form of expression and can also encourage verbal and written communication as the students reflect on the images. We believe that an increased use of art therapy should be explored when working with refugee youth.

The issue of trauma is not only a concern with refugee children, but within the family system as well. Our research indicated the strong presence of family in the lives of these 17 children. Their individual interviews alluded to the stressors and sadness with which their parents were struggling. Additionally, children are at the mercy of parental decisions, often based on inadequate information, about ways in which to relieve economic burdens. As an example, the 17-year-old Burmese male who showed much progress as a result of his participation in the photo workshops was not able to attend the final celebration meeting. This was because his father made a rapid decision to move the family based on information he received about work at a meatpacking facility in Texas, without consulting with the refugee staff in Florida who could have advised the family about the potential negative consequences of such a move. Thus, both research and practice must continue to work in an ecological systems framework, given the consequences that occur at the microsystemic level among family members.

Another finding outside the scope of this article involves the detailed comments from over 200 teachers who attended workshops based on this project. A large number commented that they were unaware of the differences between refugees and other immigrants, and that they did not know if they had refugees in their classes. For reasons intended to protect immigrants and refugees, U.S. school administrators are not allowed to inquire about students' classifications, other than determining whether or not they are in need of English language assistance. While we applaud the importance of protecting students, we recognize problems inherent in this policy, given that it leaves educators unaware of the potential traumatic experiences with which some of their students may be coping. To overcome the problems of this policy, we recommend getting to know students well. When teachers have international students, it makes sense to find out their countries of origin. Based on that information, it is easy to learn about the circumstances of those countries, given the instant information available online. Knowledge of these circumstances can help teachers to be cognizant of potential cultural issues and traumas students from certain countries may have faced. Taking the time to learn more about students from other countries can also help them to feel supported. Refugee students have reported feeling isolated by both U.S. 
International Journal of Child, Youth and Family Studies (2012) 4.1: 546-568

peers and teachers (McBrien, 2011; Mosselson, 2007). Offering encouragement can help them to gain confidence and feel welcomed in school.

Additionally, we learned that a project such as ours not only helps the participants towards self-knowledge, it can also enlighten those working with them. In an exit interview with the refugee youth director, she noted the following about how her staff had grown as a result of the project:

It's so easy for this to get focused in on the work, and we've got paper work to do, and we've got deadlines to meet, we've got all these things to do. So you sometimes lose touch a little bit. But coming and sitting and listening to the kids, sitting with them while they were writing their essays, and listening to them talk about the quotes, what was in their pictures, the staff was moved. Several of them got very emotional about some of the stuff that the kids were talking about. I got phone calls late at night, e-mails on the weekend. It made a big impression on them.

Ongoing research can benefit everyone working with refugee students, especially research that moves away from psychopathological models to ones of growth and success. In spite of their encounters with trauma and the ensuing potential for PTSD and other psychological distress, refugee youth ought not be viewed through a deficit lens. Many exemplify great resilience and are successful academically and socially (McBrien, 2009).

Continuing issues of worldwide political and social unrest result in ongoing refugee needs that seem to change only with respect to which nations are presently experiencing such tumult. At the time of this writing, the United States anticipates more arrivals from Iraq (a result of the recent war) and Burma (due to its repressive government). Frequently, people become refugees because of their desire for freedom and human rights, or because of something as unchangeable as their racial or ethnic status. The social implications of helping refugee students to become successful in their host country and to feel supported by academic institutions are obvious, in that supportive institutions contribute not only to individual well-being but also to an inclusive society. 
International Journal of Child, Youth and Family Studies (2012) 4.1: 546-568

\section{References}

Armstrong, K. B. (2005). Autophotography in adult education: Building creative communities for social justice and democratic education. New Directions for Adult and Continuing Education, 107, 33-44.

Azerbaijan International (AI). (2000, Winter). Self portrait photo exhibition: Refugees tell their own story. Retrieved July 11, 2009 from

2000http://azer.com/aiweb/categories/magazine/84_folder/84_articles/84_refugees_selfp ortrait.html

Barona, A., \& Miller, J. A. (1994). Short acculturation scale for Hispanic youth (SASH-Y): A preliminary report. Hispanic Journal of Behavioral Sciences, 16(2), 155-162.

Bebic, S. (2009, January). New refugee groups in Florida. Presentation delivered at the Adapting to a Changing World: Promising Practices in the Acculturation Process for Refugees Conference, Miami, Florida.

Berry, J. W. (1974). Psychological aspects of cultural pluralism. Topics in Culture Learning, 2, 17-22.

Brekke, J. P. (2003). “While we were waiting...”: Photography as a communicative tool in social research. Oslo, Norway: Institute for Social Research. Retrieved October 2, 2007 from http://www.socialresearch.no/Publications/Papers/2003/2003-011.

Briski, Z., \& Kauffman, R. (Producers \& Directors). (2004). Born into brothels [Motion Picture/Documentary]. United States: Velocity Home Entertainment.

Bronfenbrenner, U. (1979). The ecology of human development: Experiments by nature and design. Cambridge, MA: Harvard University Press.

Bronfenbrenner, U. (1986). Ecology of the family as a context for human development: Research perspectives. Developmental Psychology, 22(6), 723-742.

Brunick, L. L. (1999). Listen to my picture: Art as a survival tool for immigrant and refugee students. Art Education, 52(4), 12-17.

Cohen, L., Manion, L., \& Morrison, K. R. (2007). Research methods in education (6th ed.). London: Routledge Falmer.

Cummins, J. (1981). Age on arrival and immigrant second language learning in Canada: A reassessment. Applied Linguistics, 2, 132-149.

Del Valle, P., McEachern, A. G., \& Sabina, M. Q. (1999). Using drawings and writings in a group counseling experience with Cuban rafter children, "los balseritos". Guidance and Counselling, 14(4), 20-28. 
International Journal of Child, Youth and Family Studies (2012) 4.1: 546-568

Eisenbruch, M. (1988). The mental health of refugee children and their cultural development. International Migration Review, 22(Summer), 282-300.

Florida Department of Children and Families. (2012). Refugee Service Program quick facts. Retrieved June 14, 2012 from http://www.dcf.state.fl.us/programs/refugee/quickFacts.shtml.

Gallo, M. L. (2002). Picture this: Immigrant workers use photography for communication and change. Journal of Workplace Learning, 14(2), 49-57.

Gibson, M. A. (1998). Promoting academic success among immigrant students: Is acculturation the issue? Educational Policy, 12(6), 615-633.

Kirova, A., \& Emme, M. (2006). Using photography as a means of phenomenological seeing: "Doing phenomenology" with immigrant children. Indo-Pacific Journal of Phenomenology, 6, 1-12.

Martin, D. C. (2011). Refugees and asylees: 2010. Annual flow report of Homeland Security. Retrieved June 14, 2012 from http://www.dhs.gov/xlibrary/assets/statistics/publications/ois_rfa_fr_2010.pdf.

McBrien, J. L. (2005). Uninformed in the information age: Why media necessitate critical thinking education. In G. Schwarz \& P. U. Brown (Eds.), Media literacy: Transforming curriculum and teaching (pp. 18-34). Malden, MA. Blackwell Publishing.

McBrien, J. L. (2009). Beyond survival: School-related experiences of adolescent refugee girls and their relationship to motivation and academic success. In G. Wiggan \& C. Hutchinson (Eds.), Global issues in education: Pedagogy, policy, school practices and the minority experience (pp. 294-330). Lanham, MD: Rowman \& Littlefield.

McBrien, J. L. (2011). Including immigrant and refugee students. In J. Fauske, J. Carr, \& P. Jones (Eds.), Leading for inclusion: Meeting the needs of all learners in a diverse society (pp. 136-149). New York: Teachers College Press.

McBrien, J. L., \& Ford, J. C. (2012). Serving the needs of refugee children and families: An evaluation of a multi-layered community program. In M. Vickers \& F. McCarthy (Eds.), Achieving equity in education for refugee and immigrant students series. International Advances in education: Global initiatives for equity and social justice (pp. 107-126). Charlotte, NC: Information Age Publishing.

Miller, K. (2004). Beyond the frontstage: Trust, access, and the relational context in research with refugee communities. American Journal of Community Psychology, 33(3/4), 217227.

Monger, R., \& Yankay, J. (2012). Annual flow report: U.S. legal permanent residents: 2011. Washington, DC: U.S. Department of Homeland Security. Retrieved June 14, 2012 from http://www.dhs.gov/xlibrary/assets/statistics/publications/lpr_fr_2011.pdf. 
International Journal of Child, Youth and Family Studies (2012) 4.1: 546-568

Mosselson, J. (2007). Masks of achievement: An experiential study of Bosnian female refugees in New York City schools. Comparative Education Review, 51(1), 95-115.

Noland, C. M. (2006). Auto-photography as research practice: Identity and self-esteem research. Journal of Research Practice, 2(1), 1-19.

Portes, A., \& Zhou, M. (1993). The new second generation: Segmented assimilation and its variants. Annals of the American Academy of Political and Social Science, 530(1), 74-96.

Rousseau, C., Lacroix, L., Singh, A., Gauthier, M. F., \& Benoit, M. (2005). Creative expression workshops in school: Prevention programs for immigrant and refugee children. The Canadian Child and Adolescent Psychiatry Review, 14(3), 77-80.

Roytburd, L., \& Friedlander, M. L. (2008). Predictors of Soviet Jewish refugees' acculturation: Differentiation of self and acculturative stress. Cultural Diversity \& Ethnic Minority Psychology, 14(1), 67-74.

Shriberg, J., Downs-Karkos, S., \& Weisberg S. (2012). Non-formal education as a means of supporting the well-being of resettled refugees: Case studies of community approaches in Denver, Colorado. In L. Demrdjian (Ed.), Education, refugees and asylum seekers (pp. 131-150). London: Continuum International Publishing Group.

Strauss, A., \& Corbin, J. (1998). Basics of qualitative research: Techniques and procedures for developing grounded theory (2nd ed.). Thousand Oaks, CA: Sage Publications.

Stewart, J. (2011). Supporting refugee children: Strategies for educators. Toronto: University of Toronto Press.

Szente, J., Hoot, J., \& Taylor, D. (2006). Responding to the special needs of refugee children: Practical ideas for teachers. Childhood Education Journal, 34(1), 15-20.

Trickett, E. J., \& Birman, D. (2005). Acculturation, school context, and school outcomes: Adaptation of adolescent refugees from the former Soviet Union. Psychology in the Schools, 4(1), 27-38.

Yohani, S. C. (2008). Creating an ecology of hope: Arts-based interventions with refugee children. Child and Adolescent Social Work Journal, 25(4), 309-323. 